Article

\title{
When Legitimacy Shapes Environmentally Responsible Behaviors: Considering Exposure to University Sustainability Initiatives
}

\author{
Lesley Watson ${ }^{1, *}$, Karen A. Hegtvedt ${ }^{2}$, Cathryn Johnson ${ }^{2}$, Christie L. Parris ${ }^{3}$ \\ and Shruthi Subramanyam ${ }^{4}$ \\ 1 Statistics and Evaluation Center, American Cancer Society, 250 Williams St., Atlanta, GA 30303, USA \\ 2 Department of Sociology, Emory University, 1555 Dickey Drive, Atlanta, GA 30322, USA; \\ khegtv@emory.edu (K.A.H.); cjohns@emory.edu (C.J.) \\ 3 Department of Sociology, Oberlin College, 101 N. Professor St., Oberlin, OH 44074, USA; cparris@oberlin.edu \\ 4 Booth School of Business, University of Chicago, 5807 Woodlawn Ave., Chicago, IL 60637, USA; \\ ss7190@gmail.com \\ * Correspondence: watsonlesleya@gmail.com; Tel.: +1-404-329-4338 \\ Academic Editor: Michael Brody \\ Received: 9 October 2016; Accepted: 6 January 2017; Published: 11 January 2017
}

\begin{abstract}
This study examines how perceptions of the legitimacy of university sustainability efforts - support by the administration (authorization) or from students' peers (endorsement) - as well as the physical context in which students live, matter in shaping students' environmentally responsible behaviors (ERBs). Using survey data collected from fourth-year students at a university in the Southeastern US, we employ Seeming Unrelated Regression to analyze the impact of perceived legitimacy and context on recycling and conservation behaviors, controlling for demographic characteristics, pro-environmental attitudes, and environmental identity. Our findings indicate that students' perceptions of what university administrators support affect the likelihood of students to enact recycling and conservation behaviors, and peer support influences conservation behaviors. This research contributes to the literature on legitimacy by examining how legitimacy processes work in natural, rather than experimental, settings.
\end{abstract}

Keywords: environmentally responsible behaviors; legitimacy; university administration

\section{Introduction}

In the United States (US), individuals and institutions increasingly emphasize environmentally responsible behavior (ERB), whether in the form of recycling bottles, using reusable grocery bags, or investing in hybrid cars and solar panels. College campuses constitute a part of this movement as well, with recycling efforts, energy saving competitions, and "green" methods of construction (see [1]). American institutions of higher education formally acknowledged their commitment to ERBs by signing the Talloires Declaration in 1990 and the American College and University Presidents Climate Commitment (ACUPCC) in 2007.

Two goals of this green movement on college campuses are to increase student awareness about sustainability and shape related ERBs. As an important component of these efforts, campus-housing initiatives involve green construction, operation, and programming. Research illustrates that educational programs and campus demonstrations enhance the likelihood that students will perform sustainable behaviors such as recycling or turning off lights [2,3], and that living in green buildings can increase the frequency of self-reported recycling and environmental advocacy behaviors [4]. Universities use such initiatives to create and maintain a culture of sustainability in which ERB becomes common practice by all university actors. 
The present study examines how perceptions of university sustainability efforts help to shape students' ERBs. Although previous research demonstrates university effects on ERBs, rarely do studies ask why such effects emerge. Using a legitimacy framework $[5,6]$, we argue that perceived university support for sustainability efforts enhances students' frequency of enacting such behavior owing to an obligation to comply and abide by collective norms. Johnson, Dowd and Ridgeway argue "Something is legitimate if it is in accord with the norms, values, beliefs, practices, and procedures accepted by a group" [7] (p. 55).

Given that students are embedded in an institutional culture with particular values and norms, and surrounded by their peers both residentially and academically, we consider legitimacy stemming from two sources. We examine support from people occupying positions of authority in the organizational hierarchy, labeled "authorization," and support from individuals' peers, labeled "endorsement." We capture these sources of legitimacy in terms of respondents' perceptions that administrative authorities and other students at the university encourage the enactment of ERBs. We also consider the role of physical context (i.e., where students live) in fostering legitimacy perceptions as well as behavior.

Key findings that emerge from the study have implications for further research on factors shaping ERBs as well as university sustainability efforts. The extant literature on antecedents to ERBs focuses primarily on how individual-level factors such as environmental attitudes and identities [8,9] affect ERBs (see [10] for a review). This study aims to determine how contextual and legitimacy processes affect ERBs, in addition to these individual-level factors. Furthermore, our findings contribute to legitimacy research by examining how legitimacy affects behavior outside of the laboratory [5], and by exploring possible antecedents to perceptions of legitimacy.

We begin with a discussion of university sustainability efforts and the role of the university context in ERBs. We then turn to our distinct theoretical focus, providing an overview of social psychological literature on legitimacy and applying it to understanding ERB. Data to test our hypotheses come from survey responses from fourth-year students at a private university in the Southeastern US. Our analysis includes controls for individual-level factors known to affect students' behaviors, such as environmental attitudes and identities.

\subsection{University Sustainability Efforts and Legitimacy Processes}

\subsubsection{University Efforts and the Role of Context in Sustainability}

While sustainability initiatives at institutions of higher education take a variety of different forms, Barlett and Chase identify several key features that compose the core of such initiatives at many campuses: (1) leadership for sustainability; (2) institutionalizing a curriculum around sustainability; (3) incorporating green building design; (4) engaging the campus population and surrounding community on sustainability issues, and (5) creating a system-wide framework to foster sustainability [11]. While a growing body of literature is exploring how curriculum design affects students' ERBs (see [12]), this study expands to consider the involvement of university administrators in developing sustainable buildings, particularly residence halls. Sustainable residence halls often involve "green" construction and operation, as well as educational opportunities. The construction and operations components reflect the guidelines of Leadership in Energy and Environmental Design (LEED) for buildings, which pertain to building materials, water and energy efficiency, use of natural resources, indoor environmental quality, and the like. The education component may include green programming events, guest speakers, community service, and group outings. These programs often link to broader sustainability initiatives at universities such as recycling and energy contests.

Generally, studies show that university sustainability initiatives favorably affect undergraduate students' ERBs. For example, programs that create positive attitudes toward recycling or provide feedback about how much recyclable material has been collected enhance students' recycling behaviors $[2,13,14]$. Likewise, programs focused on conservation behaviors, such as the use of 
reusable grocery bags, have been successful on college campuses [15]. Furthermore, initiatives to provide feedback about energy conservation, including energy competitions among residence halls, generally result in increased awareness with regard to energy expenditures as well as decreased consumption $[3,16]$. Indeed, Kahler argues that green structures generally have positive, enduring effects on environmental behaviors and identities [17], and research has confirmed her speculation [4].

Essentially, what these previous studies propose is that exposure to various types of sustainability practices tends to have a positive effect on undergraduate ERBs. At a general level, that exposure involves providing ready access to recycling in on-campus residences and other buildings. Unlike students residing off campus who must rely upon city or county programs for recycling, on-campus residents are likely to find certain ERBs easy to enact. Additionally, universities may afford students with the opportunity to live in green dorms, thus creating daily encounters with features such as dual flush grey water toilets, automatic lights, and sustainable building materials as well as participating in green programming. The experience of "living green" represents manifestations of university sustainability policies. Presumably, such mere exposure [18] through living on-campus or in green dorms may enhance the likelihood that students will engage in ERBs. Thus:

Hypothesis 1. The extent of exposure to university sustainability efforts is positively related to students' reported frequency of ERBs.

While there is empirical evidence that contextual factors such as sustainability programming and green construction affect ERBs, studies largely fail to conceptualize why such effects occur or to address how a campus's culture of sustainability more generally may enhance ERBs. (Most of the studies assessing the impact of university initiatives are empirical, with little or no theoretical framing. Occasionally, researchers will employ theoretical notions about the attitude-behavior relationship (e.g., [2]).) We argue that legitimacy processes help to account for why university sustainability efforts work.

\subsubsection{Legitimacy Processes}

Social psychological research on legitimacy emphasizes how individuals' perceptions of what other people do in support of a particular action, rule (e.g., norm or procedure), or belief influence their behaviors. Although many things may be legitimated [19], we focus here on the legitimacy of environmental norms and behaviors. We first detail such processes and then highlight briefly the ways in which university sustainability efforts, focused on certain practices and behaviors, have become legitimated. We conclude by specifying how students' perceptions of authorization and endorsement are likely to affect their ERBs.

Drawing upon Weber's conception of legitimacy [20], Dornbush and Scott argue that legitimation occurs when a social order is in accordance with the norms and beliefs that individuals perceive as widely shared [21]. They distinguish between individual and collective level notions. Propriety refers to approval of a specific social norm at the individual-level such that a person believes that the specific social norms at issue "are desirable and appropriate patterns of action" [7] (p. 55). In contrast, validity represents approval of the social norm at the collective level and entails the individual's belief that he or she is obliged to obey these norms regardless of personal approval [5,7]. Individuals might have personal beliefs that differ from the larger community, but they recognize that the community supports a particular norm that nonetheless governs their behavior. Thus, although individuals may hold different personal beliefs, because of the validity of norms, they nonetheless comply with them [7].

Zelditch and Walker augment the notion of validity by focusing on collective sources of legitimacy, detailing how collective support can maintain legitimation of an action, rule, or belief $[5,6,22]$. One source of legitimation, authorization, occurs when support comes from authorities or one's superiors who occupy higher positions in a hierarchy. A second source, endorsement, involves the support of peers or those at a similar or lower position in a hierarchy for a particular action, rule, or belief. This study considers the effects of both authorization and endorsement on ERBs. 
Zelditch argues that an action, rule, or belief is valid if it is thought to be normative and incorporated into everyday practice [23]. With a valid norm or behavior, individuals observe that others act in accordance with it and likewise come to support it. Individuals are more likely to comply with the norm and enact the behavior if they (a) consider it a duty to do so; (b) expect that others will do so; and (c) believe that they will receive negative sanctions-either formal or informal—for noncompliance. Performing the behavior corresponding to a legitimated norm indicates compliance.

Research shows that authorization and endorsement enhance the validity of an action, rule, or belief. In a series of experimental studies, Zelditch and Walker demonstrate that individuals are more likely to comply with a particular structure — even if it does not benefit them directly—if authorities support the structure [5,6]. By doing so, individuals avoid formal sanctions from authorities for noncompliance. Similarly, people are more likely to comply with a particular action, rule, or belief if their peers support it, thus avoiding informal sanctions [24,25].

While the previous research involves experimental manipulations of authorization and endorsement, in everyday life such legitimacy structures may not be explicit and thus their impact may depend upon how those in an organization perceive them. Such is the case with recent university endeavors to promote sustainability practices. Although some such practices may save money for the institution, they are also designed to build a culture of sustainability that strengthens students' perceptions of themselves in relation to their environment and as environmentally responsible citizens. Thus, we focus here on how students' perceptions of authorization and endorsement of sustainability initiatives affects their ERBs.

\subsubsection{Effects of (Perceived) Legitimacy on Environmentally Responsible Behaviors}

In the event that a university engages in the initiatives described by Barlett and Chase [11], it signals its commitment to sustainability. Some universities have become pioneers in the sustainability movement as evidenced by their incorporation of initiatives such as green building plans, alternative transportation programs, administrative offices of sustainability that focus on the environment, reduction in energy usage, availability of recycling bins, support for the provision of locally grown foods in the dining halls, introduction of sustainability issues in courses across the curriculum, and development of degree programs related to sustainability. The support provided by administrators legitimates or, more specifically, authorizes, sustainability practices on campus. While these structures directly and indirectly encourage ERBs, students may have varying perceptions of the extent to which the university supports these practices. Thus, this study addresses how students' perceptions of the legitimacy of sustainability initiatives affect their ERBs.

To the extent that the university supports sustainability initiatives and students perceive that support, they are more likely to act in accord with the behavioral norms represented by the initiatives. Thus:

Hypothesis 2a. Perceived authorization of ERBs is positively related to students' reported frequency of ERBs.

Furthermore, support for university sustainability initiatives does not always move from the top down. Many sustainability initiatives come from the bottom-up in the form of grassroots activities implemented by students [26]. The university context is an interesting environment in which to study endorsement, given that students are surrounded by their peers in their home and social environments. We expect that to the extent students perceive their peers support sustainable behaviors, they will be more likely to act accordingly. Thus:

Hypothesis $\mathbf{2 b}$. Perceived endorsement of ERBs is positively related to students' reported frequency of ERBs.

\subsection{Sustainable Contexts as a Foundation for Legitimacy}

While we expect legitimacy processes to affect students' ERBs, it is also possible that the context itself plays a role in students' perceptions of legitimacy. As previously noted, the policies and practices 
of a university signal to students the extent of support for sustainability, yet students still have varied perceptions of authorization in this shared context. Such variation may stem, in part, from the extent to which students are exposed to the university policies and practices. Students who live on campus have greater access to university recycling and energy competitions, and increased exposure to administrators, faculty, and programming designed to communicate pro-environmental messages. Furthermore, students who live or have lived in green structures have the opportunity to witness a commitment to sustainability in the physical infrastructure of the university. To examine this relationship, we predict:

Hypothesis 3a. The extent of exposure to university sustainability efforts is positively related to students' perceived authorization of ERBs.

We also explore the possibility that increased exposure to university sustainability efforts could strengthen perceived endorsement of ERB. Studies show that behavior modeling of ERBs from peers helps students establish subjective norms about how they should behave by observing the behavior of others [27]. Students who live on campus have maximal exposure to peers in academic and residential settings, which may afford them greater additional opportunities to witness behavior modeling. Furthermore, residents of green dorms have maximum exposure to peers within an environment that facilitates such behaviors for students. Thus, context may also impact perceptions of endorsement. To the extent that students' peers are engaged in ERBs, then, we suspect that students' living arrangements may be related to their perceptions of endorsement and predict:

Hypothesis $\mathbf{3 b}$. The extent of exposure to university sustainability efforts is positively related to students' perceived endorsement of ERBs.

Attention to the relationship between context and legitimacy perceptions allows us to examine whether perceived authorization and endorsement mediate the relationship between context and reported ERBs. We hypothesize that that physical context will have effects on ERBs and perceptions of legitimacy. It may be the case, however, that context will have direct effects on perceptions of legitimacy, and indirect effects on ERBs through perceived legitimacy. We explore this possibility as we examine the relationships between these factors.

\subsection{Individual-Level Predictors of ERB}

The present study aims to move beyond individual-level factors to consider the role of educational institutions in affecting ERB by exposing students to sustainability initiatives and legitimating ERB. It is important, however, to be mindful of individual variation across students within an institution. Literature reviews and meta-analyses and have identified attitudes as an important antecedent of ERB $[10,28,29]$. Subsequent studies provide evidence that environmental identity, or an individual's sense of personal connection to his or her environment, can serve as an even stronger predictor of ERB than attitudes $[4,8,9]$. With that in mind, we include pro-environmental attitudes and environmental identity as control variables in our model, in addition to socio-demographic characteristics.

\section{Materials and Methods}

\subsection{Sample and Procedures}

We drew respondents from the population of fourth-year students at a medium-sized private university in the Southeastern US. When these students initially arrived on campus, they were among the first cohort at the university to have access to two LEED certified "green" residence halls for first-year students, complete with features such as dual flush toilets, recycling centers, sensor activated lighting, and a water reclamation system. Beyond their environmentally friendly features, the green dorms attracted students owing to their new construction and direct proximity to fraternities, sororities, and the student union. Roughly half of the students in our sample lived in these green dorms, while 
the other half resided in conventional dorms in their first year on campus. When assigning students to dorms, Residence Life officials consider students' expressed interest, as well as needs to balance gender and racial differences within and across dorms. More students expressed interest in the green dorms than the number of rooms available; thus, a number of interested students were assigned to conventional dorms. Although students' assignment to the green dorms resulted in part from application essays, there was no variation in baseline data collected prior to the students' arrival on campus in their self-reported frequency of ERB. (Difference in self-reported ERB for students assigned to green and conventional dorms were not statistically significant (means of 4.40 and 4.16, respectively, $p=0.179$ ). These students also showed no variation in baseline environmental identity, a strong predictor of ERB, across dorm assignments (means of 4.74 and $4.47, p=0.188)$ ).

Our data consist of survey responses collected in spring 2012. We solicited participation through an email to all students who lived in four dormitories during their first year on campus-two of the aforementioned green dorms and two conventional dorms. The email included information regarding our study and a hyperlink to the survey. We sent follow-up emails reminding students of the survey in the following weeks. The survey took approximately 15-20 minutes to complete. We compensated respondents for their time with 15 US Dollars either in the form of an Amazon.com gift card or cash.

Of the 628 students emailed, 315 participated, for a 50\% response rate. The demographics of our respondents accurately reflect the broader cohort population. In the sample, $54 \%$ of the respondents are female. In terms of race and ethnicity, $62 \%$ of the sample is Caucasian, $23 \%$ Asian/Asian American/Pacific Islander, 8\% African American/Black, 3\% Hispanic/Latino/Chicano, and 3\% Multiracial. Their cohort is 57\% female, $43 \%$ male, $47 \%$ Caucasian, $24 \%$ Asian, $11 \%$ African American, $4 \%$ Hispanic, $7 \%$ Non-US citizen, and 7\% unknown. Coan and Holman have pointed out limitations of analyzing data from a single location to determine sustainable behaviors [30]. As a destination university, however, our participants come from a variety of locations: $40 \%$ from the Northeast US, $35 \%$ from the South, $10 \%$ from the West, $15 \%$ from the Midwest, and 3\% outside the US.

\subsection{Measures}

The survey includes questions about ERBs, perceptions of support for sustainability efforts, first-year and current living situations, demographic characteristics, environmental attitudes, and environmental identity. Multiple indicators constitute the dependent and some independent variables in our analysis. Thus, we created scales for each variable, using principal component factor analysis with a Varimax rotation and theoretical considerations. Each of these scales is additive, standardized by the number of items.

\subsubsection{Dependent Variables}

To capture students' environmental behavior during the school year, the survey asks whether respondents had engaged in a range of ERBs during the school year. All responses were measured on a 7-point Likert scale ranging from 1 (Never) to 7 (Always). We focus on 12 items that cluster into two distinct types of ERBs that students engage in regularly: recycling and conservation.

The recycling scale includes items related to the respondents' recycling behavior. This four-item scale includes the following: "During this school year, how often did you ... " (1) recycle paper; (2) recycle containers (e.g., plastic, glass, aluminum); (3) encourage family members to recycle; and (4) encourage friends to recycle. The items stem from previous studies on environmental concerns [31,32]. The scale has a Cronbach's alpha of 0.90

The conservation scale includes items pertaining to reducing the use of resources such as energy and water. The eight-item scale includes the following: "During this school year, how often did you ... " (1) turn off the faucet while brushing your teeth; (2) turn off lights when exiting a room; (3) take the stairs instead of using the elevator; (4) unplug "chargers" for phones, iPods, etc., when not in use; (5) carpool to a destination; (6) reduce paper use (e.g., print double sided); (7) reduce computer energy use (e.g., turn off monitor, use sleep mode); and (8) purchase products in reusable or recyclable 
containers. This scale includes items drawn from previous studies on sustainable behavior [32,33], as well as self-created items based on specific sustainability efforts promoted by the university. Cronbach's alpha for this scale is 0.81 .

\subsubsection{Independent Variables}

We include two measures to capture the extent of students' exposure to university sustainability efforts. We measure the type of residence hall they lived in during their first year on campus $(0=$ conventional dorm, $1=$ green dorm $)$ as well as their current residence $(0=$ off campus, $1=$ on campus).

To measure perceived authorization, we focus on institutional support for specific ERBs. Respondents used a 7-point Likert scale ranging from 1 (Not at All) to 7 (A Great Deal) to respond to the question: "How much does [the University] encourage students to..." perform the behaviors in the dependent variable measures. (Also included was the option of "Don't know" $=0$.) We created two scales from these items that parallel the ERBs of interest, excluding any "Don't know" responses from the analysis. The four-item authorization of recycling scale has a Cronbach's alpha of 0.88 , and the eight-item authorization of conservation scale has a Cronbach's alpha of 0.93.

Similarly, we asked respondents to use the same scale to answer the following question to measure endorsement: "How much do your peers on [the University] campus in general encourage each other to ... " engage in the same set of behaviors. The four-item perceived endorsement of recycling scale has a Cronbach's alpha of 0.92, and the eight-item perceived endorsement of conservation scale has a Cronbach's alpha of 0.93. In our analysis, we use the authorization and endorsement scales that correspond with the respondent behavior (e.g., authorization and endorsement of recycling matches to respondents' recycling behaviors).

\subsubsection{Control Variables}

We include demographics, individual attitudes, and environmental identity as controls. These measures pertain to factors that may affect an individual's personal engagement in ERBs. Previous research demonstrates the effects of these factors on ERBs [8,34-36]. Demographic indicators include gender $(0=$ male $)$, race $(0=$ nonwhite $)$, income, and parental education levels. Family income is measured with eight different income ranges, beginning with "less than $\$ 25,000$ " and ending with "more than $\$ 250,000 . "$ Separate questions ask about mother's and father's education level, with categories ranging from "high school graduate/ GED/less than high school" to "doctoral degree." For those participants in two-parent households, we use the mean for parents' education; for those in single-parent households, we use the education level of that parent.

To capture environmental attitudes, we use a scale that focuses on issues suggesting an environmental crisis at hand. This scale derives from work done by Milfont and Duckitt [37] and contains items from a variety of sources [34,38-40]. We measure responses on a 7-point Likert scale ranging from 1 (Strongly Disagree) to 7 (Strongly Agree). Thus, higher numbers represent more environmentally friendly attitudes. The scale asks: "How much do you disagree or agree with the following statements?" and consists of five items: (1) Humans are severely abusing the environment; (2) If things continue on their present course, we will soon experience an ecological catastrophe; (3) We are approaching the limits the earth can support; (4) The greenhouse effect is dangerous to the environment; and (5) Pesticides and chemicals are dangerous to the environment. The reliability of this scale is 0.86 .

Additionally, in order to assess how environmental identity affects ERBs and legitimacy, we measure the degree to which the environment affects a person's self-definition using a 6-item scale derived from Clayton's environmental identity scale [35]. The chosen items focus specifically on individuals' connections with the environment. (Our survey included four additional items from Clayton's scale, which we removed due to their similarity with attitude and behavior measures in the study. These are: (1) If I had enough time or money, I would certainly devote some of it to working for 
environmental causes; (2) Behaving responsibly toward the earth—living a sustainable lifestyle-is part of my moral code; (3) I spend a lot of time in natural settings (woods, mountains, desert, lakes, ocean); (4) I believe that learning about the natural world should be an important part of every child's upbringing. We ran each of our models using the 10-item version of the scale, and found no change in the pattern of results.) Respondents indicated the extent to which each statement was "not true at all of me" (1) to "completely true of me" (7). The items are: (1) Engaging in environmental behaviors is important to me; (2) Being a part of the ecosystem is an important part of who I am; (3) I think of myself as a part of nature, not separate from it; (4) I feel that I have roots to a particular geographic location that had a significant impact on my development; (5) In general, being part of the natural world is an important part of my self-image, and (6) My own interests usually seem to coincide with the position advocated by environmentalists. Cronbach's alpha for this scale is 0.89 .

\subsection{Analysis}

We used seemingly unrelated regression (SUR) to test the effects of context and legitimacy on two types of ERB, as well as the effects of context on perceived legitimacy. SUR is used in scenarios involving several dependent variables that may be related to each another [41,42]. While the different types of ERBs studied are theoretically distinct [43], they all fall within the realm of ERB. SUR estimates the equations for all the dependent variables simultaneously, considers the correlation among the errors terms for each equation, and uses those errors to improve the estimates [42]. (SUR includes all variables from each model simultaneously, which has the unintended consequence of diminishing the sample size for the model. Running models for each dependent variable separately provides a much larger $\mathrm{N}$ for each model, but does not account for correlated error terms. We ran each model separately in ordinary least squares (OLS) regression and found no differences in the substantive patterns produced by SUR and OLS analyses involving a larger N. Analyses available upon request.) The correlations between the error terms for recycling and conservation in these models are all greater than $0.94, p<0.001$, and thus SUR is appropriate to adjust for these correlations. Results for SUR are interpreted in the same way as those from ordinary least squares regression. Participants fall into two groups: those who reside on and off campus. Therefore, we cluster the analysis by current residence to address possible correlations within these groups. All non-dummy variables are centered on the mean in the SUR models.

\section{Results}

\subsection{Descriptives}

Appendixs A and B provide the means, standard deviations, and bivariate correlations for the dependent, independent, and control variables for recycling and conservation, respectively. Given that we use two types of ERBs (and corresponding measures for perceived authorization, and endorsement), we provide a separate table for the measures within these behavior types. Several patterns are noteworthy. Conservation behaviors are the most common (mean $=4.64)$, followed closely by recycling behaviors (mean $=4.35$ ). This pattern is reversed for legitimacy measures, however, with slightly higher perceptions of legitimacy for recycling than conservation. In addition, students generally perceived higher levels of authorization for recycling and conservation (4.65 and 4.42, respectively) than endorsement of these behaviors from their peers (3.94 and 3.71, respectively). The bivariate correlations indicate that students' first year dorm and current living arrangements have no significant relationships with recycling, and a weak negative relationship with conservation behaviors. Perceived authorization and endorsement are positively, but moderately, correlated.

\subsection{Context Effects}

The physical context in which students were or are embedded (i.e., green or conventional first-year dorm, and current living situation on or off campus, respectively) affects the extent of their exposure to 
university sustainability efforts. Table 1 shows the effects of context on ERBs independent of legitimacy variables (Model 1) and the full model (Model 3). We examine hypotheses in terms of results from the full model.

Table 1. Standardized Seemingly Unrelated Regression Coefficients for the Effects of Context and Legitimacy on Environmentally Responsible Behaviors $(N=226)$.

\begin{tabular}{|c|c|c|c|c|c|c|}
\hline & \multicolumn{3}{|c|}{ Recycling } & \multicolumn{3}{|c|}{ Conservation } \\
\hline & 1 & 2 & 3 & 1 & 2 & 3 \\
\hline \multicolumn{7}{|l|}{ Individual Controls } \\
\hline Female (v. male) & $\begin{array}{c}0.260 * * \\
(0.096)\end{array}$ & $\begin{array}{c}0.299 * * * \\
(0.007)\end{array}$ & $\begin{array}{c}0.308^{* * *} \\
(0.005)\end{array}$ & $\begin{array}{c}0.408^{* * *} \\
(0.024)\end{array}$ & $\begin{array}{c}0.281 * * * \\
(0.011)\end{array}$ & $\begin{array}{c}0.267^{* * *} \\
(0.002)\end{array}$ \\
\hline White (v. non-white) & $\begin{array}{l}-0.050 \\
(0.241)\end{array}$ & $\begin{array}{c}0.052 \\
(0.396)\end{array}$ & $\begin{array}{c}0.053 \\
(0.390)\end{array}$ & $\begin{array}{c}0.040 \\
(0.087)\end{array}$ & $\begin{array}{c}0.122 \\
(0.095)\end{array}$ & $\begin{array}{c}0.105 \\
(0.077)\end{array}$ \\
\hline Income & $\begin{array}{l}-0.009 \\
(0.080)\end{array}$ & $\begin{array}{c}0.005 \\
(0.072)\end{array}$ & $\begin{array}{c}0.007 \\
(0.073)\end{array}$ & $\begin{array}{c}-0.023^{* * *} \\
(0.004)\end{array}$ & $\begin{array}{l}-0.018 \\
(0.031)\end{array}$ & $\begin{array}{l}-0.025 \\
(0.034)\end{array}$ \\
\hline Parental Education & $\begin{array}{l}-0.077 \\
(0.109)\end{array}$ & $\begin{array}{l}-0.047 \\
(0.128)\end{array}$ & $\begin{array}{l}-0.047 \\
(0.119)\end{array}$ & $\begin{array}{l}-0.038 \\
(0.063)\end{array}$ & $\begin{array}{l}-0.000 \\
(0.057)\end{array}$ & $\begin{array}{l}-0.005 \\
(0.053)\end{array}$ \\
\hline Pro-Environmental Attitudes & $\begin{array}{c}0.201^{* * *} \\
(0.018)\end{array}$ & $\begin{array}{l}0.164 * \\
(0.068)\end{array}$ & $\begin{array}{l}0.163 \text { * } \\
(0.064)\end{array}$ & $\begin{array}{c}0.172 * * \\
(0.060)\end{array}$ & $\begin{array}{c}0.155^{* * *} \\
(0.033)\end{array}$ & $\begin{array}{c}0.154^{* * *} \\
(0.029)\end{array}$ \\
\hline Environmental Identity & $\begin{array}{c}0.606^{* * *} \\
(0.064)\end{array}$ & $\begin{array}{c}0.524^{* * *} \\
(0.039)\end{array}$ & $\begin{array}{c}0.526^{* * *} \\
(0.040)\end{array}$ & $\begin{array}{c}0.362^{* * *} \\
(0.044)\end{array}$ & $\begin{array}{c}0.314^{* * *} \\
(0.046)\end{array}$ & $\begin{array}{c}0.311^{* * *} \\
(0.051)\end{array}$ \\
\hline \multicolumn{7}{|l|}{ Context } \\
\hline $\begin{array}{l}\text { Green First-Year Dorm } \\
\text { (v. conventional) }\end{array}$ & $\begin{array}{l}0.199+ \\
(0.115)\end{array}$ & - & $\begin{array}{c}0.119 \\
(0.090)\end{array}$ & $\begin{array}{c}0.034 \\
(0.096)\end{array}$ & - & $\begin{array}{c}0.069 \\
(0.054)\end{array}$ \\
\hline Live On-campus (v. off) & $\begin{array}{l}-0.135 \\
(0.086)\end{array}$ & - & $\begin{array}{c}0.068 \\
(0.067)\end{array}$ & $\begin{array}{c}-0.228^{* * *} \\
(0.002)\end{array}$ & - & $\begin{array}{c}-0.225^{* * *} \\
(0.041)\end{array}$ \\
\hline \multicolumn{7}{|l|}{ Legitimacy } \\
\hline Authorization & - & $\begin{array}{c}0.131^{* * *} \\
(0.038)\end{array}$ & $\begin{array}{l}0.139^{* * *} \\
(0.035)\end{array}$ & - & $\begin{array}{l}0.109^{* * *} \\
(0.006)\end{array}$ & $\begin{array}{l}0.104^{* * *} \\
(0.009)\end{array}$ \\
\hline Endorsement & - & $\begin{array}{c}0.042 \\
(0.047)\end{array}$ & $\begin{array}{c}0.038 \\
(0.040)\end{array}$ & - & $\begin{array}{l}0.081^{* * *} \\
(0.019)\end{array}$ & $\begin{array}{l}0.095^{* * *} \\
(0.023)\end{array}$ \\
\hline Adjusted $R^{2}$ & 0.297 & 0.324 & 0.319 & 0.358 & 0.386 & 0.391 \\
\hline
\end{tabular}

Notes: $+p \leq 0.10 ;{ }^{*} p \leq 0.05 ;{ }^{* *} p \leq 0.01 ;{ }^{* * *} p \leq 0.001$.

Hypothesis 1 predicts that greater exposure to university sustainability efforts will be positively related to students' reported frequency of ERBs. As represented by having lived in a green dorm or currently residing on campus, such exposure does not have significant effects on recycling. With regard to conservation, living in a green dorm has no significant effects, while currently living on-campus actually has a negative effect on self-reported conservation behaviors $(b=-0.225, p \leq 0.001)$. Overall, these results disconfirm Hypothesis 1.

\subsection{Perceived Legitimacy Effects}

To test our second set of hypotheses, we examine the effects of both authorization and endorsement independently (Model 2), and in the full model (Model 3). We discuss hypotheses in terms of the full model. Hypothesis 2a predicts a positive relationship between perceived authorization and students' ERBs. As seen in Table 1, perceived authorization by the university is positively related to the reported frequency of recycling $(b=0.139, p \leq 0.001)$, and conservation behaviors $(b=0.104, p \leq 0.001)$, clearly confirming our hypothesis.

In Hypothesis $2 b$, we predict a positive relationship between perceived endorsement and students' ERBs. Support for this hypothesis is mixed: there is no statistically significant association between perceived endorsement and recycling, but there is a significant positive relationship between perceived endorsement and reported conservation $(b=0.095, p \leq 0.001)$.

\subsection{Context Effects for Perceived Legitimacy}

In addition to examining the effects of context and legitimacy on behavior, we propose that context may affect perceived authorization and endorsement of ERBs. Table 2 summarizes the SUR results 
for context and control variables on perceived authorization. Hypothesis 3 a predicts that living in a green first-year dorm and currently living on campus will positively affect perceived authorization. The significant effects that do emerge are not in the predicted direction, thus disconfirming the hypothesis. The negative effects suggest that living in a green first-year dorm decreases perceived authorization of conservation $(b=-0.128, p \leq 0.001)$, and currently living on campus likewise attenuates perceived authorization of recycling $(b=-0.340, p \leq 0.001)$.

Table 2. Standardized Seeming Unrelated Regression Coefficients for the Effects of Context on Perceived Authorization $(N=220)$.

\begin{tabular}{|c|c|c|}
\hline & Recycling & Conservation \\
\hline \multicolumn{3}{|l|}{ Individual Controls } \\
\hline Female (v. male) & $\begin{array}{l}0.832 * \\
(0.389)\end{array}$ & $\begin{array}{c}0.692^{* *} \\
(0.248)\end{array}$ \\
\hline White (v. non-white) & $\begin{array}{l}-0.103 \\
(0.085)\end{array}$ & $\begin{array}{l}-0.129 \\
(0.181)\end{array}$ \\
\hline Income & $\begin{array}{l}-0.007 \\
(0.086)\end{array}$ & $\begin{array}{l}-0.032 \\
(0.066)\end{array}$ \\
\hline Parental Education & $\begin{array}{c}-0.183 * \\
(0.089)\end{array}$ & $\begin{array}{c}-0.144^{* * *} \\
(0.042)\end{array}$ \\
\hline Pro-Environmental Attitudes & $\begin{array}{c}0.227 \\
(0.147)\end{array}$ & $\begin{array}{c}0.188 \\
(0.202)\end{array}$ \\
\hline Environmental Identity & $\begin{array}{c}0.165^{* * *} \\
(0.045)\end{array}$ & $\begin{array}{c}0.182 * * * \\
(0.017)\end{array}$ \\
\hline \multicolumn{3}{|l|}{ Context } \\
\hline Green First-Year Dorm (v. conventional) & $\begin{array}{l}-0.129 \\
(0.322)\end{array}$ & $\begin{array}{c}-0.128^{* * *} \\
(0.033)\end{array}$ \\
\hline Live On-campus (v. off) & $\begin{array}{c}-0.340^{* * *} \\
(0.006)\end{array}$ & $\begin{array}{c}0.042 \\
(0.030)\end{array}$ \\
\hline
\end{tabular}

Notes: ${ }^{*} p \leq 0.05 ;{ }^{* *} p \leq 0.01 ; * * * \leq 0.001$

We also explored the possibility that living arrangements could affect perceived endorsement. Hypothesis $3 \mathrm{~b}$ states that living in a green dorm during a student's first year or currently residing on-campus will have a positive effect on perceptions of endorsement. SUR results in Table 3 show the effects differ across these two measures of context. Living in a green first year dorm has no significant effect on perceived endorsement of recycling, and a negative effect on perceived endorsement of conservation $(b=-0.292, p \leq 0.001)$. Living on-campus, however, is positively associated with perceived endorsement of both recycling $(b=0.406, p \leq 0.001)$ and conservation $(b=0.285, p \leq 0.001)$, supporting our hypothesis.

By examining results in Tables 1-3, we are also able to explore whether perceived legitimacy mediates the relationship between context and ERBs. Generally, we do not find evidence of such mediation. As noted in Hypothesis 1, our results indicate that the context in which students currently or formerly lived does not have statistically significant positive effects on recycling or conservation, However, we do find evidence of a complex relationship between living on-campus, endorsement, and conservation behaviors. While living on-campus is negatively associated with self-reported conservation behaviors $(b=-0.225, p \leq 0.001)$, it is positively associated with perceived endorsement of conservation $(b=0.285, p \leq 0.001)$, which exerts positive effects on self-reported conservation behaviors $(\mathrm{b}=0.095, p \leq 0.001)$. 
Table 3. Standardized Seeming Unrelated Regression Coefficients for the Effects of Context on Perceived Endorsement $(N=210)$.

\begin{tabular}{ccc}
\hline & Recycling & Conservation \\
\hline Individual Controls & & \\
\hline Female (v. male) & 0.556 & 0.304 \\
& $(0.384)$ & $(0.279)$ \\
\hline White (v. non-white) & $-0.279+$ & -0.182 \\
& $(0.155)$ & $(0.120)$ \\
\hline Income & -0.002 & 0.024 \\
& $(0.007)$ & $(0.072)$ \\
\hline Parental Education & $-0.078^{* * * *}$ & $-0.113^{* *}$ \\
& $(0.015)$ & $(0.039)$ \\
\hline \multirow{2}{*}{ Pro-Environmental Attitudes } & $0.116^{* * *}$ & 0.073 \\
& $(0.022)$ & $(0.150)$ \\
\hline \multirow{2}{*}{ Environmental Identity } & $0.280^{* * *}$ & $0.240 * * *$ \\
& $(0.181)$ & $(0.069)$ \\
\hline Context & & $-0.292^{* * *}$ \\
\hline Green First-Year Dorm (v. conventional) & -0.281 & $(0.019)$ \\
\hline \multirow{2}{*}{ Live On-campus (v. off) } & $(0.081)$ & $0.285^{* * *}$ \\
& $0.406^{* * *}$ & $(0.074)$ \\
\hline Adjusted $R^{2}$ & $(0.002)$ & 0.095 \\
\hline Notes: $+p \leq 0.10 ;{ }^{*} p \leq 0.05 ; * *$ & $p \leq 0.01 ; * * p \leq 0.001$. &
\end{tabular}

\subsection{Effects of Control Variables}

Gender has a significant relationship with recycling and conservation, indicating that women are more likely to enact these ERBs more frequently than men. In contrast to studies that find effects of race on ERBs such as recycling and conservation [44], our results indicate no relationship between race and ERB for this population. With regard to SES, we find no relationship between income or parental education and ERBs.

Moving beyond demographic variables, we consider the effects of attitude and identity controls. Attitudes exert a significant, positive effect on recycling $(b=0.163, p \leq 0.05)$ and conservation $(b=0.154, p \leq 0.001)$. Based on previous studies $[4,8,9]$, we expected that environmental identity would exert strong, positive effects on ERBs. Results clearly confirm our expectation about the influence of environmental identity on recycling $(b=0.526, p \leq 0.001)$ and conservation $(b=0.311, p \leq 0.001)$.

\section{Discussion}

Our research integrates contextual factors and legitimacy processes to gain a clearer understanding of the antecedents of environmentally responsible behaviors (ERBs) outside of a laboratory setting. Additionally, we explore potential antecedents of legitimacy. These results have practical implications for universities trying to foster a culture of sustainability on their campuses, and non-experimental evidence of legitimacy processes. Three key conclusions emerge from our analysis.

First, the performance of ERBs by students in this sample is not affected by their living arrangements as predicted. For the fourth-year students in our study, their experience in a green first-year dorm hardly affects their current ERBs. Two reasons may account for this pattern. Most obviously, three years have passed since the experience, attenuating its impact. In addition, having lived in a dorm that makes recycling and conservation easy for students while they are residents does not guarantee they will continue those behaviors once they leave that environment. It is also 
possible that students who lived in conventional dorms increased their ERBs over the three intervening years. All our data allow us to know for certain is that first-year living arrangement has little effect on fourth-year students' ERBs at this particular university.

In regard to living on or off campus, while currently living on campus does affect ERBs, it fails to enhance them. In the absence of information on the availability of recycling programs or the infrastructure of their off-campus residences, we are unable to determine how welcoming to recycling and conservation their current residences might be. We suspect, however, that students who live off-campus may be more likely to engage in conservation behaviors than students who live on-campus for financial reasons-turning off lights and conserving water because they are responsible for paying utility costs. Future research should examine the effects of physical context by including measures of sustainable infrastructure provided by the city or county in which off-campus students live.

Second, by demonstrating that perceived legitimacy does impact sustainable behaviors, our study joins other research on the effects of legitimacy and provides an answer to why university efforts matter. As expected, perceived authorization clearly impacts recycling and conservation behavior. Indeed, the university's support for such behaviors is illustrated by providing ample opportunities to recycle throughout the campus, by posting signs throughout the campus to encourage energy conservation and waste reduction generally, and specific actions such as turning off lights and using the stairs. Perceived endorsement effects for recycling may not be significant because in the presence of ample opportunities to recycle, students do not need verbal encouragement or the fear of informal sanctions to engage in these behaviors. In contrast, perceived peer endorsement seems to improve conservation behaviors, perhaps because they require more effort from students. When universities place recycling bins next to each trashcan, this infrastructure and strong authorization may be sufficient to produce the behavior. Conservation behaviors such as turning off lights, taking the stairs instead of elevators, or conserving water may more likely be impacted by witnessing peer behavior modeling and establishing norms around such activities because they take more effort in general.

Importantly, we find effects of perceived authorization and endorsement on ERBs while controlling for environmental attitudes and identities-two individual-level factors that exert consistent effects on ERBs in the literature (e.g., $[4,8,9]$ ). Our study provides further evidence of the importance of attitudes and identity on ERBs, and shows that perceptions of legitimacy also serve as antecedents to these behaviors. Furthermore, we find effects for perceived legitimacy even in the absence of concern for potential sanctions or noncompliance. As previously described, formal sanctions from authorities and informal ones from peers constitute a key theorized mechanism of legitimacy processes. In the case of ERBs, the university and possibly even students' peers have few avenues for sanctions, suggesting that the effects of perceived legitimacy on ERBs are rather robust. Future studies should examine the conditions under which sanctions are necessary for legitimacy processes, which would include designing measures to tap into perceptions of sanctions from authorities and peers.

Finally, our study provides a glimpse at rarely investigated (outside of studies on procedural justice, see $[45,46]$ ) contextual antecedents of perceived legitimacy (Hypotheses 3a and 3b). Given the resources that universities use to build sustainable dorms, it is surprising that their former residents do not perceive greater authorization of ERBs. The negative effects of green dorm residence on perceived authorization and endorsement of conservation may result from heightened expectations. Students who lived in these dorms may perceive less support for conservation precisely because they expect other dorms and buildings on campus, as well as their peers, to strongly promote conservation after being initially exposed to a dorm that facilitates green living.

Notably, findings indicate that living on campus negatively affects perceived authorization of recycling. We suspect that this finding may be related to the materials that may be recycled on campus. The university recycling center is not equipped to recycle glass bottles, and students who live on campus have raised concerns that this prevents them from being able to recycle wine and beer bottles. Glass recycling may have less of an effect on students living off campus, as they may be less likely to consume alcohol while on campus during the day. Living on campus does, however, increase perceived 
endorsement for recycling and conservation, presumably by allowing students more opportunities to witness their peers engaging in such ERBs within their residences. While living on campus may make students less likely to conserve energy because they do not pay the cost of their own utilities, it does increase their perceptions of peer support for such behaviors, which has a positive, albeit smaller, effect on conservation behaviors. Future longitudinal research might untangle the meaning and impact of living on campus on perceptions of legitimacy over the course of students' residency on campus.

Our research design allows us to consider how perceptions may vary within the same context, but fails to provide a comparison among university contexts. Future studies that compare universities with different sustainability policies and programs may extend knowledge on how university policies and practices affect both legitimacy perceptions and behaviors [47].

This research makes a novel contribution by bringing together legitimacy theory with a practical problem of developing a culture and cultivating particular behaviors among university students. Our findings also suggest important policy implications for universities that wish to promote ERBs among students. Our results highlight the importance of university leadership, while also pointing to limitations of targeted initiatives such as themed green dorms. While these dorms may be effective at eliciting ERB from residents who currently live there, these residents may not continue to engage in ERB after they move out, and may even perceive less support of sustainability from the university based on comparisons to their experience within green dorms. Thus, it is important for universities to establish broad sustainability initiatives to reach all students across the university, rather than investing solely in targeted initiatives that may fail to have long-lasting effects. Overall, however, our findings indicate the importance of university leadership-if universities support ERBs, providing ample opportunities for recycling and conservation, they will engage students in more of these behaviors, especially as they see their peers doing them as well.

Acknowledgments: The data presented in this research were collected with support from Woodruff Funds provided by Emory University and a Spencer Foundation Grant (20120061) to Cathryn Johnson and Karen A. Hegtvedt. We would like to acknowledge the assistance of Emily Cumbie-Drake and Jaspal Bhatia in the development of the survey and data collection.

Author Contributions: Karen A. Hegtvedt and Cathryn Johnson conceived the study; Karen A. Hegtvedt, Cathryn Johnson, Lesley Watson, and Christie L. Parris designed data collection instruments. Shruthi Subramanyam conducted initial analyses for a student honor's thesis. Lesley Watson revised the analysis and wrote the paper, with support from Karen A. Hegtvedt, Cathryn Johnson, and Christie L. Parris.

Conflicts of Interest: The authors declare no conflict of interest. The funding sponsors had no role in the design of the study; in the collection, analyses, or interpretation of data; in the writing of the manuscript, and in the decision to publish the results. 


\section{Appendix A}

Table A1. Recycling Correlation Matrix with Means (and Standard Deviations) on Diagonal.

\begin{tabular}{|c|c|c|c|c|c|c|c|c|c|c|c|c|}
\hline \multirow{2}{*}{$\begin{array}{c}\text { Variables } \\
\text { (Named and Numbered) }\end{array}$} & \multicolumn{12}{|c|}{ Variables (Numbered) } \\
\hline & 1 & 2 & 3 & 4 & 5 & 6 & 7 & 8 & 9 & 10 & 11 & 12 \\
\hline 1. Respondent Behavior & $4.35(1.60)$ & & & & & & & & & & & \\
\hline 2. Female (v. Male) & 0.061 & $0.54(0.50)$ & & & & & & & & & & \\
\hline 3. White (v. Nonwhite) & 0.020 & -0.015 & $0.62(0.49)$ & & & & & & & & & \\
\hline 4. Income & -0.032 & -0.034 & $0.393 * * *$ & $5.31(2.22)$ & & & & & & & & \\
\hline 5. Mother's Education & -0.037 & 0.014 & $0.238^{* * *}$ & $0.432 * * *$ & $4.23(1.55)$ & & & & & & & \\
\hline 6. Father's Education & -0.069 & -0.007 & $0.144^{*}$ & $0.355^{* * *}$ & $0.523^{* * *}$ & $4.76(1.78)$ & & & & & & \\
\hline $\begin{array}{l}\text { 7. Pro-environmental } \\
\text { Attitudes }\end{array}$ & $0.349^{* * *}$ & $0.209^{* * *}$ & -0.000 & -0.028 & -0.061 & -0.015 & $5.24(1.07)$ & & & & & \\
\hline $\begin{array}{l}\text { 8. Environmental } \\
\text { Identity }\end{array}$ & $0.568^{* * *}$ & -0.053 & 0.048 & -0.025 & 0.014 & -0.017 & $0.470^{* * *}$ & $4.35(1.32)$ & & & & \\
\hline $\begin{array}{l}\text { 9. Green Dorm } \\
\text { (v. Conventional) }\end{array}$ & -0.009 & -0.095 & 0.054 & 0.036 & 0.079 & 0.045 & -0.086 & -0.048 & $0.44(0.50)$ & & & \\
\hline $\begin{array}{l}\text { 10. Live On-campus } \\
\text { (v. Off) }\end{array}$ & -0.060 & -0.047 & $-0.156^{* *}$ & $-0.221^{* * *}$ & -0.114 & -0.074 & 0.022 & -0.018 & $0.146^{*}$ & $0.51(0.50)$ & & \\
\hline 11. Authorization & $0.324^{* * *}$ & $0.258^{* * *}$ & -0.045 & $-0.138^{*}$ & $-0.197^{* *}$ & -0.101 & $0.237^{* * *}$ & $0.212^{* * *}$ & $-0.129 *$ & -0.071 & $4.65(1.65)$ & \\
\hline 12. Endorsement & $0.315^{* * *}$ & $0.171 *$ & -0.105 & -0.114 & 0.108 & -0.097 & $0.243^{* * *}$ & $0.303^{* * *}$ & -0.095 & 0.124 & $0.558^{* * *}$ & $3.94(1.53)$ \\
\hline
\end{tabular}




\section{Appendix B}

Table B1. Conservation Correlation Matrix with Means (and Standard Deviations) on Diagonal.

\begin{tabular}{|c|c|c|c|c|c|c|c|c|c|c|c|c|}
\hline \multirow{2}{*}{$\begin{array}{c}\text { Variables } \\
\text { (Named and Numbered) }\end{array}$} & \multicolumn{12}{|c|}{ Variables (Numbered) } \\
\hline & 1 & 2 & 3 & 4 & 5 & 6 & 7 & 8 & 9 & 10 & 11 & 12 \\
\hline 1. Respondent Behavior & $4.64(1.10)$ & & & & & & & & & & & \\
\hline 2. Female (v. Male) & $0.201^{* * *}$ & $0.54(0.50)$ & & & & & & & & & & \\
\hline 3. White (v. Nonwhite) & 0.049 & -0.015 & $\begin{array}{l}00.62 \\
(0.49)\end{array}$ & & & & & & & & & \\
\hline 4. Income & -0.057 & -0.034 & $0.393^{* * *}$ & $5.31(2.22)$ & & & & & & & & \\
\hline 5. Mother's Education & -0.052 & 0.014 & $0.238^{* * *}$ & $0.432^{* * *}$ & $4.23(1.55)$ & & & & & & & \\
\hline 6. Father's Education & -0.048 & -0.007 & $0.144 *$ & $0.355^{* * *}$ & $0.523^{* * *}$ & $4.76(1.78)$ & & & & & & \\
\hline $\begin{array}{l}\text { 7. Pro-environmental } \\
\text { Attitudes }\end{array}$ & $0.447^{* * *}$ & $0.209^{* * *}$ & -0.000 & -0.028 & -0.061 & -0.015 & $5.24(1.07)$ & & & & & \\
\hline $\begin{array}{l}\text { 8. Environmental } \\
\text { Identity }\end{array}$ & $0.577^{* * *}$ & -0.053 & 0.048 & -0.025 & 0.014 & -0.017 & $0.470^{* * *}$ & $4.35(1.32)$ & & & & \\
\hline $\begin{array}{l}\text { 9. Green Dorm } \\
\text { (v. Conventional) }\end{array}$ & $-0.123 *$ & -0.095 & 0.054 & 0.036 & 0.079 & 0.045 & -0.086 & -0.048 & $0.44(0.50)$ & & & \\
\hline $\begin{array}{l}\text { 10. Live On-campus } \\
\text { (v. Off) }\end{array}$ & $-0.123 *$ & -0.047 & $-0.156^{* *}$ & $-0.221^{* * *}$ & -0.114 & -0.074 & 0.022 & -0.018 & $0.146^{*}$ & $0.51(0.50)$ & & \\
\hline 11. Authorization & $0.365^{* * *}$ & $0.222 * * *$ & -0.091 & $-0.166 *$ & $-0.199 * *$ & -0.118 & $0.248^{* * *}$ & $0.246^{* * *}$ & 0.024 & 0.025 & $4.42(1.46)$ & \\
\hline 12. Endorsement & $0.377^{* * *}$ & 0.113 & -0.086 & -0.056 & -0.120 & -0.116 & $0.191^{* *}$ & $0.269 * * *$ & -0.117 & 0.056 & $0.640^{* * *}$ & $3.71(1.35)$ \\
\hline
\end{tabular}

Notes: ${ }^{*} p \leq 0.05 ; * * p \leq 0.01 ; * * * p \leq 0.001$. 


\section{References}

1. Miller, H. Creating a Culture of Sustainability: How Campuses Are Taking the Lead. Available online: http://www.hermanmiller.com/hm/content/research_summaries/wp_Campus_Sustain.pdf (accessed on 5 October 2016).

2. Goldenhar, L.M.; Connell, C.M. Understanding and Predicting Recycling Behavior: An Application of the Theory of Reasoned Action. J. Enviro. Syst. 1993, 22, 91-103. [CrossRef]

3. Marcell, K.; Agyeman, J.; Rappaport, A. Cooling the campus: Experiences from a pilot study to reduce electricity use at Tufts University, USA, using social marketing methods. Int. J. Sustain. Higher Educ. 2004, 5, 169-189. [CrossRef]

4. Watson, L.; Johnson, C.; Parris, C.L.; Hegtvedt, K.A. Living Green: Examining Sustainable Dorms and Identities. Int. J. Sustain. Higher Educ. 2015, 16, 310-326. [CrossRef]

5. Walker, H.A.; Zelditch, M., Jr. Power, Legitimation, and the Stability of Authority: A Theoretical Research Program. In Theoretical Research Programs: Studies in the Growth of Theory; Berger, J., Zelditch, M., Jr., Eds.; Stanford University Press: Stanford, CA, USA, 1993; pp. 364-381.

6. Zelditch, M., Jr.; Walker, H.A. Legitimacy and the Stability of Authority. Adv. Group Process. 1984, 1, 1-25.

7. Johnson, C.; Dowd, T.J.; Ridgeway, C. Legitimacy as a Social Process. Annual Rev. Sociol. 2006, 32, 53-78. [CrossRef]

8. Stets, J.E.; Biga, C.F. Bringing identity theory into environmental sociology. Sociol. Theory 2003, 21, $389-423$. [CrossRef]

9. Whitmarsh, L.; O'Neill, S. Green identity, green living? The role of pro-environmental self-identity in determining consistency across diverse pro-environmental behaviours. J. Environ. Psychol. 2010, 30, 305-314. [CrossRef]

10. Gifford, R.; Nilsson, A. Personal and social factors that influence pro-environmental concern and behavior: A review. Int. J. Psychol. 2014, 49, 141-157. [PubMed]

11. Barlett, P.F.; Chase, G.W. Sustainability on Campus: Stories for Change; MIT Press: Cambridge, MA, USA, 2004.

12. Frisk, E.; Larson, K.L. Educating for sustainability: Competencies and practices for transformative action. J. Sustain. Educ. 2011, 2, 1-20.

13. Katzev, R.; Mishima, H.R. The Use of Posted Feedback to Prompt Recycling. Psychol. Rep. 1992, 71, $259-264$. [CrossRef]

14. Schultz, P.W. Examining the Effects of Recycling Outreach on Recycling Behavior in Residence Halls at the University of California, Berkeley. Available online: nature.berkeley.edu/classes/es196/projects/2002final/ Schultz.pdf (accessed on 5 October 2016).

15. Barlow, L.K. Implementing Behavioral Change in Residence Halls at the University of Colorado at Boulder: Energy Conservation and Reusable Bags. Available online: http:/ / envs.colorado.edu/uploads/undergrad/ Energy_Conservation_Reusable_Bags_report.pdf (accessed on 4 October 2016).

16. Petersen, J.E.; Shunturov, V.; Janda, K.; Platt, G.; Weinberger, K. Dormitory residents reduce electricity consumption when exposed to real-time visual feedback and incentives. Int. J. Sustain. Higher Educ. 2007, 8, 16-33. [CrossRef]

17. Kahler, S. The ripple effect: How one dorm room can affect a university's energy use. Int. J. Sustain. Higher Educ. 2003, 4, 230-238. [CrossRef]

18. Bornstein, R.F. Exposure and Affect: Overview and Meta-Analysis of Research, 1968-1987. Psychol. Bull. 1989, 106, 265-289. [CrossRef]

19. Zelditch, M., Jr. Processes of legitimation: Recent developments and new directions. Soc. Psychol. Q. 2001, 64, 4-17. [CrossRef]

20. Weber, M. Economy and Society; Roth, G., Wittich, C., Eds.; University of California Press: Berkeley, CA, USA, 1978.

21. Dornbusch, S.M.; Scott, R. Evaluation and the Exercise of Authority; Jossey-Bass: San Francisco, CA, USA, 1975.

22. Zelditch, M., Jr.; Walker, H.A. The Legitimacy of Regimes. Adv. Group Process. 2003, 20, 217-249.

23. Zelditch, M., Jr. Legitimacy Theory. In Contemporary Social Psychological Theories; Burke, P.J., Ed.; Stanford University Press: Stanford, CA, USA, 2006; pp. 324-352.

24. Johnson, C.; Ford, R.; Kaufman, J. Emotional Reactions to Conflict: Do Dependence and Legitimacy Matter? Soc. Forces 2000, 79, 107-137. [CrossRef] 
25. Walker, H.A.; Thomas, G.M.; Zelditch, M., Jr. Legitimation, Endorsement, and Stability. Soc. Forces 1986, 64, 620-643. [CrossRef]

26. Brinkhurst, M.; Rose, P.; Maurice, G.; Ackerman, J.D. Achieving campus sustainability: Top-Down, bottom-up, or neither? Int. J. Sustain. Higher Educ. 2011, 12, 338-354. [CrossRef]

27. Routhe, A.S.; Jones, R.E.; Feldman, D.L. Using Theory to Understand Public Support for Collective Actions that Impact the Environment: Alleviating Water Supply Problems in a Nonarid Biome. Soc. Sci. Q. 2005, 86, 874-897. [CrossRef]

28. Hines, J.M.; Hungerford, H.R.; Tomera, A.N. Analysis and synthesis of research on responsible environmental behaviour: A meta-analysis. J. Environ. Educ. 1987, 18, 1-8. [CrossRef]

29. Bamberg, S.; Moser, G. Twenty years after Hines, Hungerford, and Tomera: A new meta-analysis of psycho-social determinants of pro-environmental behaviour. J. Environ. Psychol. 2007, 27, 14-25. [CrossRef]

30. Coan, T.G.; Holman, M.R. Voting Green. Soc. Sci. Q. 2008, 89, 1121-1135. [CrossRef]

31. Milfont, T.L.; Duckitt, J. The structure of environmental attitudes: A first- and second-order confirmatory factor analysis. J. Environ. Psychol. 2004, 24, 289-303. [CrossRef]

32. Pendarvis, S.S. SUI Student Survey Preliminary Results. Available online: www.sc.edu/sustainableu/ studentsurvey.pdf (accessed on 6 October 2016).

33. Harland, P.; Staats, H.; Wilke, H.A.M. Explaining proenvironmental intention and behavior by personal norms and the theory of planned behavior. J. Appli. Soc. Psychol. 1999, 29, 2505-2528. [CrossRef]

34. Biga, C.F. Explaining environmentally significant individual behaviors: Identity theory, multiple identities, and shared meanings. Ph.D. Thesis, Washington State University, Pullman, WA, USA, 2006.

35. Clayton, S. Environmental identity: A conceptual and an operational definition. In Identity and the Natural Environment: The Psychological Significance of Nature; The MIT Press: Cambridge, MA, USA, 2003; pp. 45-65.

36. Sparks, P.; Shepherd, R. Self-identity and the theory of planned behavior: Assessing the role of identification with “green consumerism". Soc. Psychol. Q. 1992, 55, 388-399. [CrossRef]

37. Milfont, T.L.; Duckitt, J. The environmental attitudes inventory: A valid and reliable measure to assess the structure of environmental attitudes. J. Environ. Psychol. 2010, 30, 80-94. [CrossRef]

38. Barkan, S. Explaining public support for the environmental movement: A civic voluntarism. Soc. Sci. Q. 2004, 85, 913-937. [CrossRef]

39. Dunlap, R.E.; Van Liere, K.D.; Mertig, A.G.; Jones, R.E. Measuring endorsement of the new ecological paradigm: A revised NEP scale. J. Soc. Issues 2000, 56, 425-442. [CrossRef]

40. Stern, P.C.; Dietz, T.; Kalof, L. Value orientations, gender, and environmental concern. Environ. Behav. 1993, 25, 322-348. [CrossRef]

41. Minnotte, K.L.; Mannon, S.E.; Pederson Stevens, D.; Kilger, G. Does it take a village to make a marriage? Exploring the relationship between community and marital satisfaction. Sociol. Focus 2008, 41, 119-136. [CrossRef]

42. Timm, N.H. Applied Multivariate Analysis; Springer: New York, NY, USA, 2002.

43. Stern, P.C. Toward a coherent theory of environmentally significant behavior. J. Soc. Issues 2000, 56, 407-424. [CrossRef]

44. Parker, J.D.; McDonough, M.H. Environmentalism of African Americans: An analysis of the subculture and barriers theories. Environ. Behav. 1999, 31, 155-177. [CrossRef]

45. Tyler, T.R. Psychological Perspectives on Legitimacy and Legitimation. Annu. Rev. Psychol. 2006, 57, 375-400. [CrossRef] [PubMed]

46. Tyler, T.R. Legitimacy and Rule Adherence: A Psychological Perspective on the Antecedents and the Consequences of Legitimacy. In The Psychology of Justice and Legitimacy; Bobocel, D.R., Kay, A.C., Zanna, M.P., Olson, J.M., Eds.; Psychology Press: New York, NY, USA, 2010; pp. 251-271.

47. Borek, E.; Bohon, S.A. Policy Climates and Reductions in Automobile Use. Soc. Sci. Q. 2008, 89, $1293-1311$. [CrossRef]

(c) 2017 by the authors; licensee MDPI, Basel, Switzerland. This article is an open access article distributed under the terms and conditions of the Creative Commons Attribution (CC-BY) license (http://creativecommons.org/licenses/by/4.0/). 